\title{
Capacity of the national influenza surveillance system in Afghanistan, a chronic conflict setting
}

\author{
M.H. Rasooly', M.N. Sahak ${ }^{2}$, K.I. Saeed ${ }^{3}$, S.K. Krishnan ${ }^{4}$, W. Khan ${ }^{5}$ and S. Hassounah ${ }^{6}$
}

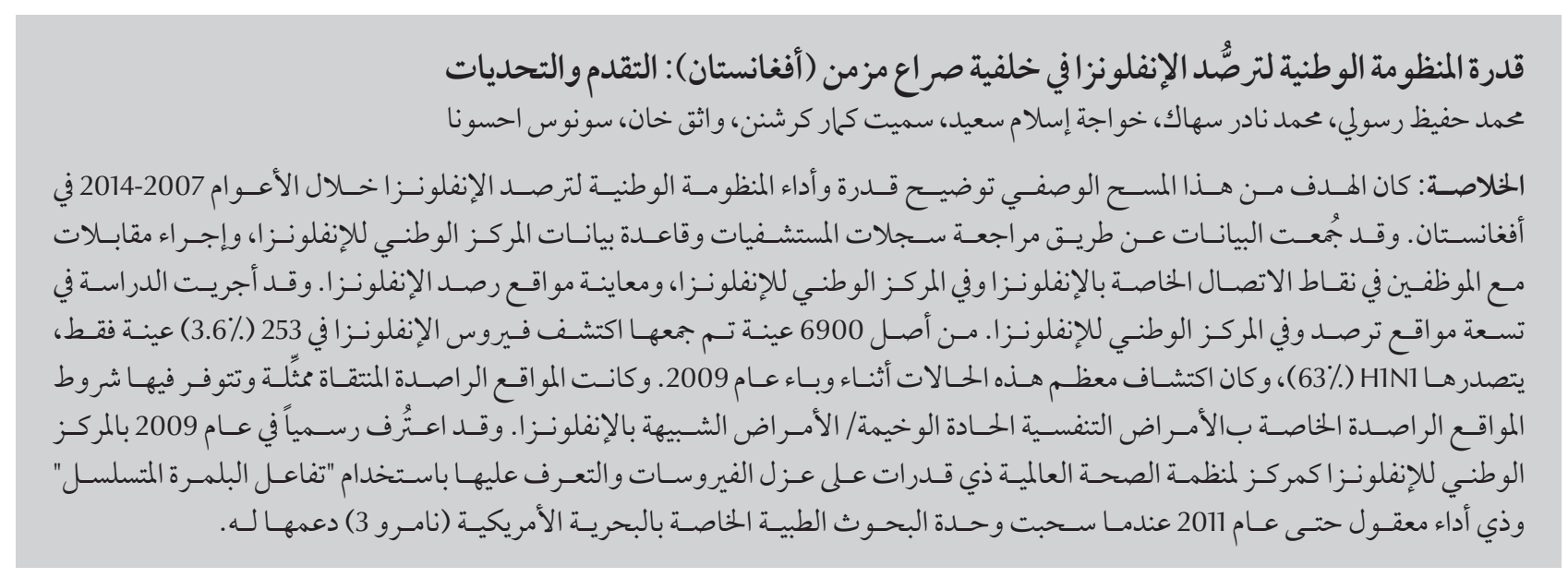

ABSTRACT Influenza surveillance is needed to monitor potential public health threats from the emergence of novel influenza viruses. This study assessed the capacity and performance of the national influenza surveillance system in Afghanistan from 2007 to 2014. Data were collected by review of hospital registers and the National Influenza Centre (NIC) database, interviews with influenza focal points at 9 influenza sentinel surveillance sites and the Centre staff, and observation of the sites. Out of 6900 specimens collected, influenza virus was detected in 253 (3.6\%), predominantly H1N1 (63\%); most of these cases were detected during the 2009 pandemic. The NIC had the capacity for virus isolation and PCR identification and performed reasonably until 2011 when support of the Naval American Medical Research Unit 3 was withdrawn. The limitations identified in the system indicated the need for: more complete data, improved technical competence and trained human resources, updating of the infrastructure/facilities, and the presence of standard operating procedures throughout surveillance.

\section{Capacité du système national de surveillance de la grippe en Afghanistan, une situation de conflit chronique}

RÉSUMÉ La surveillance de la grippe est nécessaire pour contrôler les menaces de santé publique potentielles au moment de l'émergence de nouveaux virus de la grippe. La présente étude a évalué la capacité et la performance du système national de surveillance de la grippe en Afghanistan de 2007 à 2014. Les données ont été recueillies en examinant les registres des hôpitaux et la base de données du Centre national de la grippe (CNG), en interrogeant les points focaux pour la grippe sur neuf sites de surveillance sentinelle ainsi que le personnel du CNG, et en observant les sites. Sur les 6900 échantillons prélevés, le virus de la grippe a seulement été identifié dans 253 d'entre eux (3,6\%); il s'agissait essentiellement du H1N1 (63\%). De plus, la majorité de ces cas ont été dépistés au cours de la grippe pandémique de 2009. Le CNG avait la capacité d'isolement et d'identification par PCR du virus. II a en outre obtenu des résultats satisfaisants jusqu'à ce que la troisième Unité de recherche médicale de la Marine américaine (NAMRU-3) lui retire son soutien en 2011. Les insuffisances identifiées dans le système indiquent la nécessité d'obtenir des données plus complètes, d'améliorer les compétences techniques et d'avoir des ressources humaines formées, de rénover les infrastructures/locaux, et de disposer de modes opératoires normalisés pour l'ensemble du processus de surveillance.

'Surveillance Department, Ministry of Public Health, Kabul, Afghanistan (Correspondence to M.H. Rasooly: influenza.surveillance@ gmail.com). ${ }^{2}$ World Health Organization Country Office, Kabul, Afghanistan. ${ }^{3}$ Surveillance Department, Ministry of Public Health, Kabul, Afghanistan. ${ }^{4}$ Communicable Disease Surveillance, World Health Organization Country Office, Kabul, Afghanistan. ${ }^{5}$ Pandemic Influenza Preparedness, World Health Organization Regional Office for the Eastern Mediterranean, Cairo, Egypt. ${ }^{6}$ WHO Collaborating Centre for Public Health Education \& Training, Department of Primary Care and Public Health, Imperial College London, London, United Kingdom.

Received: 30/04/16; accepted: 22/08/16 


\section{Introduction}

Afghanistan has experienced considerable conflict and political turmoil in the past several decades. The unstable security and political situation in the country has taken a heavy toll on the country's economy and remains a main concern of Afghans (1-3). In spite of the challenging conditions, health indicators in Afghanistan have been improving $(4,5)$.

The association of conflict with emerging infections is well documented; factors such as rapid displacement of populations, ineffective disease surveillance, poor access to health and other social services and an overall weak health system make the population more susceptible to infectious diseases and hinder detection and control of emerging infectious (6).

Limited information was available on communicable diseases in Afghanistan and there were no data on circulating influenza viruses before 2006 since no disease surveillance existed. Therefore, the Ministry of Public Health (MoPH) Afghanistan, with the support of the Centers for Disease Control and Prevention (CDC), Atlanta and the Naval American Medical Research Unit 3 (NAMRU-3), established the influenza surveillance system in 2007 which was predominantly laboratory surveillance. In this regard, the National Influenza Centre (NIC) was established within the structure of Central Public Health Laboratory Kabul.

There were documented cases/ outbreaks of influenza A subtypes in the country in both humans and animals $(7,8)$ and seasonal influenza $\mathrm{A}(\mathrm{H} 1 \mathrm{N1})$ was circulating among humans. However, influenza A (H5N1) was reported only in poultry (9-11); avian cases of H5N1 were confirmed between 2006 and 2009 in 5 of the 34 provinces of Afghanistan: Kabul, Kunar, Laghman, Maidan-Wardak and Nangarhar, and in backyard poultry (chickens) in 22 outbreak sites. There was no record of human cases.

The first cases of pandemic influenza A (H1N1) were reported among foreign military personnel at Bagram Airbase in June 2009 and the Central Public Health Laboratory confirmed the first civilian case in the second week of July $2009(10,11)$.

In 2011, the surveillance directorate of the MOPH and $\mathrm{CDC}$ reviewed the influenza surveillance system. The country had 9 severe acute respiratory infection (SARI)/influenza-like illness (ILI) sentinel surveillance sites with a specific sample collection scheme. The specimen collection scheme was set up for both the acute respiratory infections (ARI) season (October-March) and thenon-ARI season (April-September) as evident from the national surveillance data as a proxy for the influenza season. As epidemiological surveillance was not established, the focus of the influenza surveillance system was virological.

After 2011, because of contractual issues with the $\mathrm{CDC}$ funding process and withdrawal of NAMRU-3 support, there was a decrease in laboratory support and the influenza surveillance system was unable to achieve its objectives. Given the global public health concern about the emergence of novel pathogenic influenza viruses and the importance therefore of surveillance to detect and respond to such threats, the World Health Organization (WHO) decided in 2014 to support influenza surveillance in Afghanistan through the Pandemic Influenza Preparedness (PIP) project. Since its establishment in 2007, there has been no comprehensive picture of the existing influenza surveillance system. To fill this knowledge gap, under the PIP 2014 plan, an assessment of the existing influenza surveillance system was carried out. The objective of this assessment was to ascertain the capacity of the sentinel surveillance sites and the National Influenza Centre (NIC), and review the influenza surveillance data for 2007-2014.

\section{Methods}

\section{Study setting}

The assessment covered all 9 SARI/ ILI surveillance sites which were located in 8 geographical regions of the country (the central region has 2 sentinel site in Kabul and Kapisa provinces) and included Indira Gandhi Hospital Kabul (National), Balkh, Herat, Kandahar and Nangarhar, regional hospitals, and Bamyan, Kapisa, Kunduz and Paktya, provincial hospitals.

\section{Study period}

Data collection started on 7 December 2014 and was completed on 6 January 2015.

\section{Design}

This was a descriptive survey consisting of retrospective review of existing data, staff interviews and direct observation. A retrospective review of the hospital register for medical wards and Health Management Information System records for all admissions of lower respiratory tract infections was conducted to get a sense of which diagnostic codes or clinical diagnoses were being used to identify SARI. The number of admissions and deaths due to the lower respiratory tract infections were extracted from the register and HMIS records for the year 2014. In addition, the NIC database was also reviewed to determine the performance of sentinel based SARI/ILI surveillance sites and the NIC between 2007 and 2014.

Face-to-face interviews were conducted with disease early warning system (DEWS) focal points and NIC staff at their work stations. The questions for these interviews focused on site description, human resources capacity (including training, knowledge and use of SARI/ ILI case definitions), method of data collection and analysis, specimen collection, storage, and shipment and site infrastructure. Similarly in the interview with the NIC staff, the main questions were about 
NIC infrastructure, specimen quality at reception, processing and testing, data management and analysis, reporting, quality control, and biosafety and the biosecurity measures in place.

Direct observation was also conducted to verify the SARI/ILI case selection, availability of data collection forms, specimen collection process, availability of personal protective equipment, other equipment and consumables.

For all above data, 2 data collection tools were prepared and adapted for the Afghan context. The first one was adapted from the CDC International Influenza Surveillance Assessment Tool (12) for the SARI/ILI sentinel site assessment; it covered site description, number of outpatients and inpatients, data on lower respiratory tract infections' admissions and deaths for 2014, human resources, knowledge of staff about SARI/ILI, infrastructure and laboratory capacity at sentinel site (specimen collection, packaging, storage and shipment capacity). The second tool was developed by WHO for the NIC assessment. It covered general information about the NIC, specimen processing and testing, data management, tracking and analysis, reporting, specimen quality and site monitoring (13).

\section{Data collection and analysis}

The data collection teams, who were part of the technical surveillance staff of the MOPH, were provided a brief training on the data collection tools by surveillance experts at the MOPH. The teams consisted of one regional surveillance coordinator and one laboratory technician from the NIC. Both interviewed the influenza surveillance focal points separately and noted their site observations using the tools accordingly. Data collection was monitored and data were reviewed at the central level at the MOPH to check for inconsistencies. Once cleaned, they were entered into Epi Info 7. Descriptive analysis was performed using SPSS, version 20.

\section{Results}

\section{Data from the influenza surveillance system (2007-2014)}

From 2007 to 2012, the system registered 6900 suspected influenza cases from all sentinel surveillance sites and specimens were collected. Out of 6900 specimens, influenza virus was detected in 253 (3.7\%). The majority of the cases 199 (78.7\%) were detected during the 2009 pandemic influenza in Afghanistan which represented $11 \%$ of total specimens (1809) collected in 2009. Children and adults aged $15-<50$ years were more likely to have an influenzapositive sample those $<5$ and $\geq 50$ years (Figure 1). The proportion of positive cases was higher among males 169 (66.8\%) than female 84 (33.2\%). Most laboratory-confirmed cases were influenza A (H1N1) 160 (63.2\%) followed by influenza A (not subtyped/untyped) 64 (25.3\%), influenza B 20 (7.9\%) and influenza A (H3N2) 9 (3.6\%) (Figure 2). About half of all the cases detected were from Kabul province (51.0\%) followed by Herat (10.3\%), Bamyan (5.1\%), Balkh (4.7\%) and Nangarhar (4.3\%). The rest of the cases were from various other provinces. (Figure 3 showing map of Afghanistan and depicting equal geographical distribution of sites).

The data for 2013/14 were incomplete. The hospitals used case definitions for respiratory tract infections (RTIs) for all admitted cases with pneumonia due to any infection in children and adults and all other respiratory

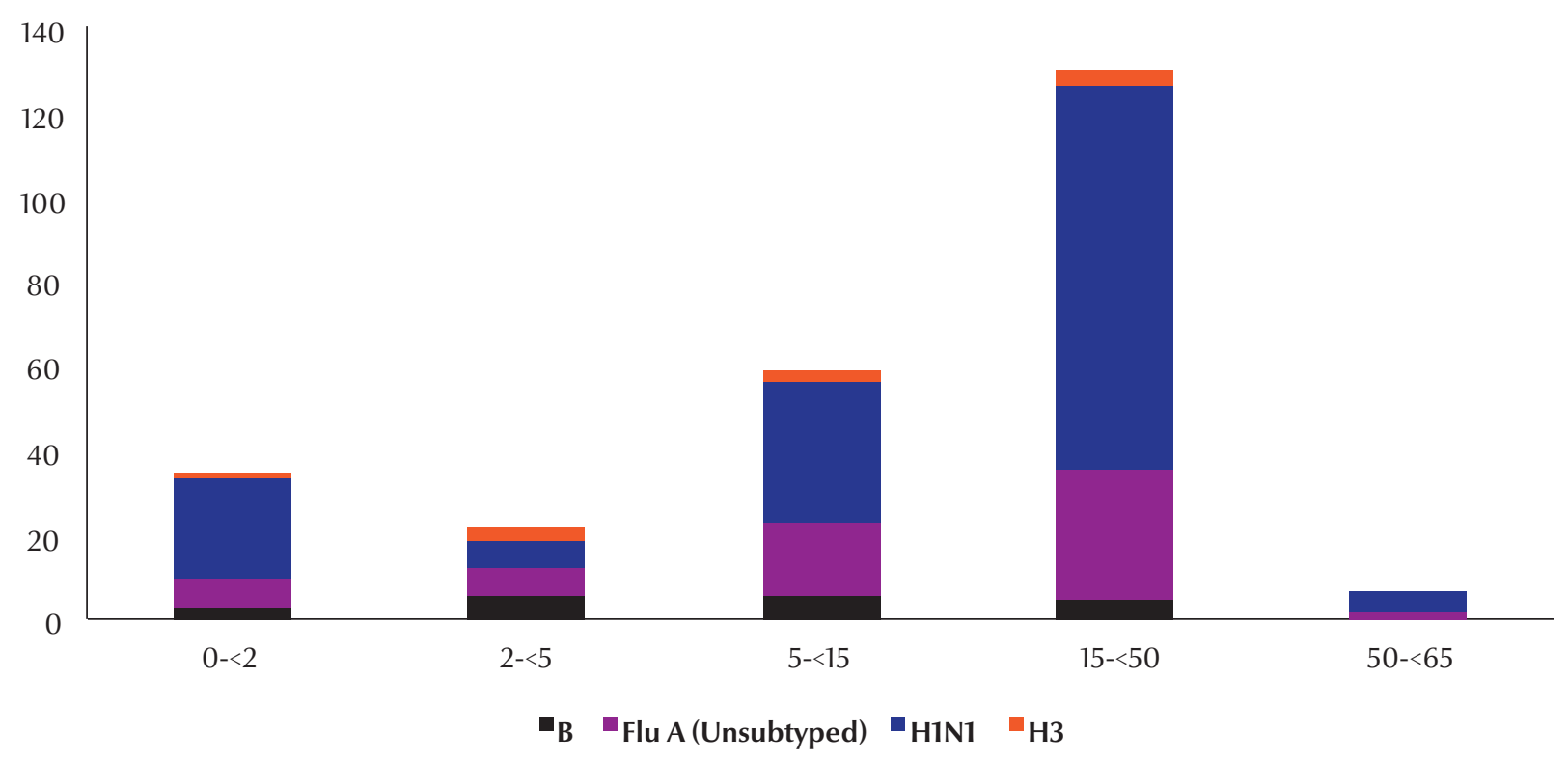

Figure 1 Number of influenza viruses isolated by type and age group (2007-2012) 


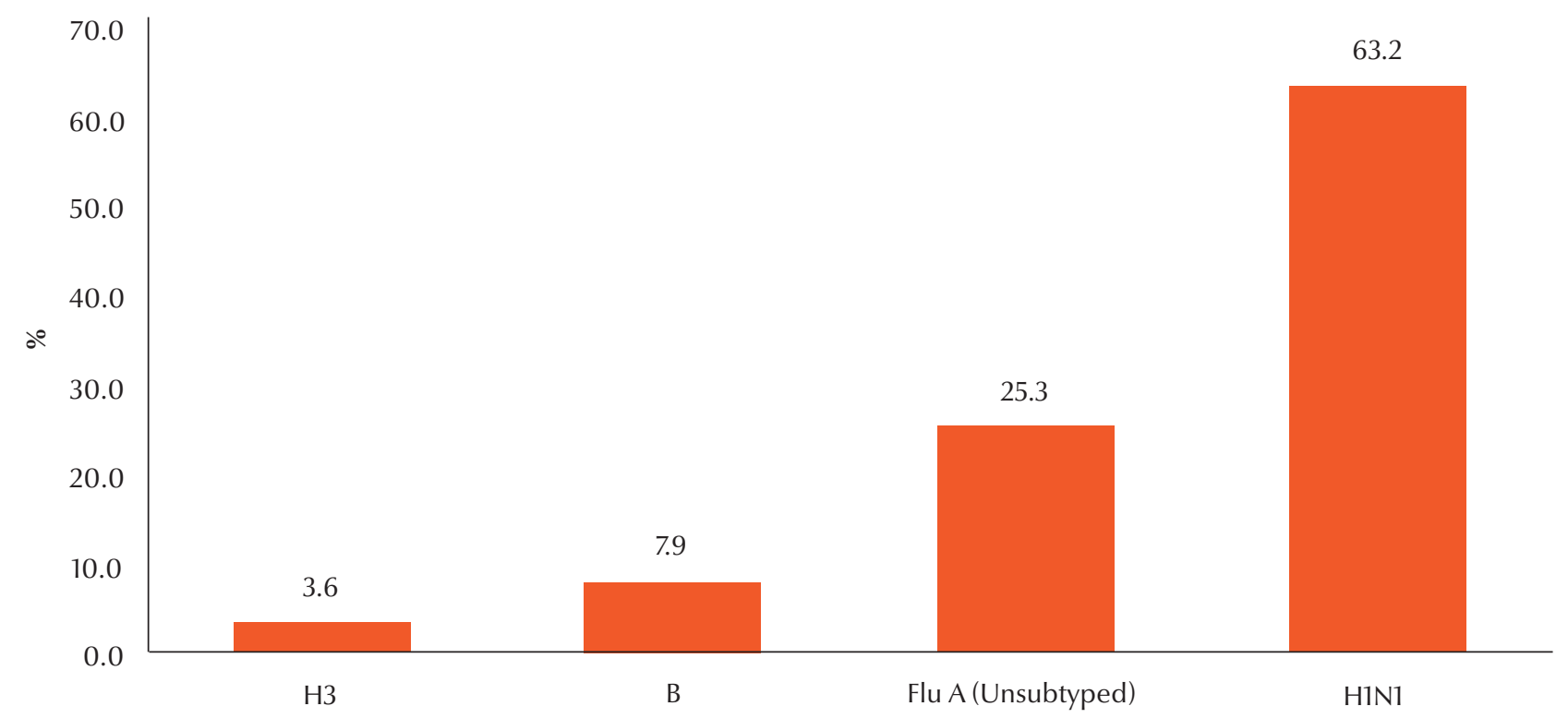

Figure 2 Distribution (\%) of influenza virus type detected during 2007-2012 ( $n=6900)$

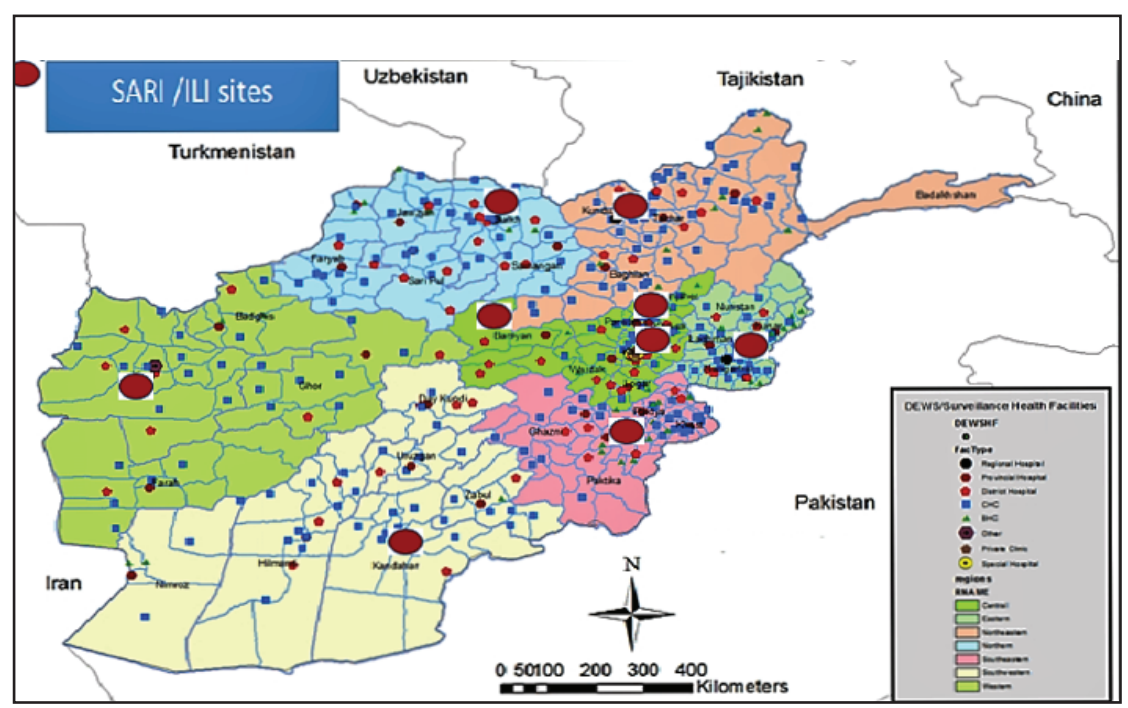

Figure 3 Map of SARI/ILI surveillance sites

illnesses associated with any infections. Nangarhar regional hospital had the highest admission of RTIs (4277 cases) followed by Balkh Regional Hospital (3553) and Indira Gandhi Paediatric Hospital in Kabul (3539) in 2014. (Figure 4). The overall mortality rate due to the admitted RTIs was 40 per 1000 RTI admissions.

\section{Overview of influenza sentinel surveillance sites}

Assessment was carried out in 9 SARI/ ILI-designated surveillance sites in Kabul, Kapisa, Balkh, Kunduz, Herat, Kandahar, Paktya, Bamyan and Nangarhar provinces. The sites represented the 8 geographical regions in major cities of Afghanistan and were located in the national, regional and provincial hospitals All these hospitals provided outpatient and inpatient services hence the same sites operated for both SARI and ILI surveillance. For inpatients, the log book included the name, age, sex, residence and provisional diagnosis but did not record signs, symptoms, temperature or final diagnosis. The hospitals served all age groups and also pregnant women.

There was no reliable power supply in Herat regional hospital, Paktya provincial hospital, Kunduz provincial hospital and Indira Gandhi Paediatric Hospital in Kabul. Few sites had access to a refrigerator within the hospitals itself, while others sent the samples for preservation to the cold chain facilities of other national health programmes outside the hospitals, such as immunization or the surveillance offices.

\section{Human resources and procedures at the sites}

All the hospitals were covered under the national disease surveillance system (Disease Early Warning System, DEWS, which was started in 2007) and the hospital management teams had agreed for their facilities to be used as 


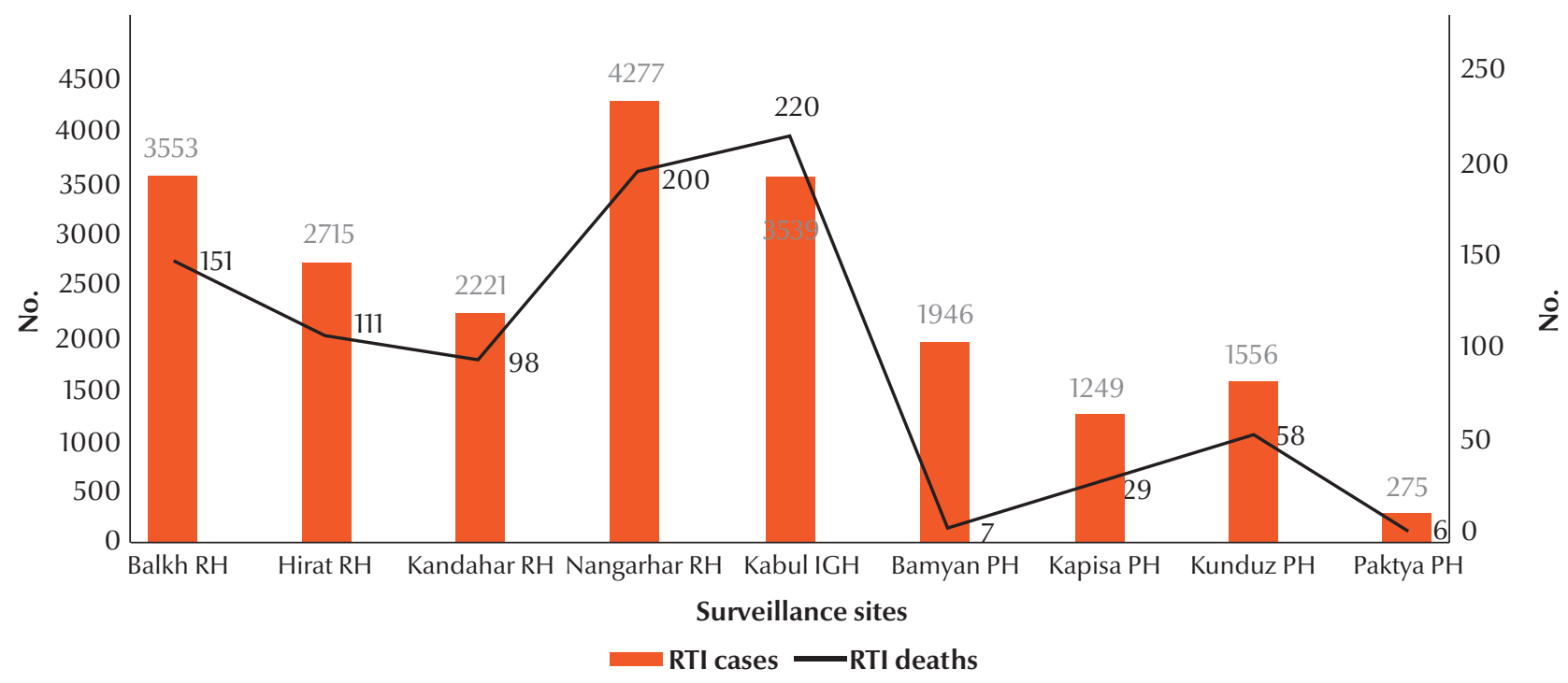

Figure 4 Hospitalized respiratory tract infection (RTI) cases and deaths in selected SARI/ILI surveillance sites, $2014(\mathrm{RH}=$ regional hospital; $\mathbf{P H}$ = provincial hospital; $\mathbf{I G H}=$ Indira Gandhi Hospital)

SARI/ILI surveillance sites also. DEWS focal points in 6 of the 9 sentinel sites (Bamyan, Herat, Kandahar, Kunduz, Nangarhar and Paktya) used the SARI case definition; however, in most of the sites visited, the SARI/ILI case definitions were not posted or visible for other health service providers. Although all the focal points had received some training on sample collection for disease surveillance under DEWS, none had received specific training on SARI/ILI surveillance or specimen collection.

All the sites used the same data collection form designed for ILI as there was no separate standard data collection form for SARI. In some sites, such as Balkh, Kandahar and Nangarhar, the forms were not easily available in the focal point's office, and in most sites there was no specific fixed day or time for SARI/ILI data and specimen collection.

Despite clear guidelines regarding the number of specimens to be collected per week, none of the sites followed the guidelines. Specimens were usually sent to the NIC in Kabul each week. The mean number of SARI specimens collected per week was 2.5 during the ARI season and 1.7 during the rest of the year for the period 2007 to 2014. Three of the 9 sites (Balkh, Kunduz and Indira Gandhi Hospital in Kabul) did not collect specimens from SARI cases mainly due to the unavailability of supplies and designated trained staff.

None of the sites used standard triple packaging; the specimens were placed in Ziploc plastic bags, which were then kept in vaccine carriers (specific for samples only) and sent to NIC in Kabul by local transport under cold chain. The assessment team found that there were no written guidelines on SARI/ILI specimen collection, packaging, storage or transport.

\section{National Influenza Centre: capacity}

The NIC was formally recognised as a WHO national influenza centre in 2009 with the development of capacities for virus isolation and polymerase chain reaction (PCR) identification. The Centre has the capacity to isolate $\mathrm{H1}, \mathrm{H} 3, \mathrm{~B} 1$ and $\mathrm{B} 2$ viruses by reverse transcriptase PCR and virus culture. The laboratory isolated type B influenza virus for the first time in the country in 2007 and forwarded it to NAMRU-3 for further characterization. The laboratory has a testing algorithm and most samples are tested for type, subtype and strain, but since no gene sequencer is available, no genotyping is done. The laboratory can test a maximum of 30 samples per week, and SARI/ILI samples are stored until testing at $-70^{\circ} \mathrm{C}$.

After the withdrawal of the NAMRU-3 staff at the end of 2011 , virus isolation was discontinued (due to failure of survival of MDCK cell line) and the laboratory functioned sub-optimally. PCR tests, although available, were not performed regularly which resulted in a huge backlog of samples and results were not reported on a regular basis to the influenza surveillance unit at $\mathrm{MOPH}$.

In the current assessment of the Centre, there were no biosecurity measures in place, such as identification badges, freezer locks and restricted access or security cameras. In addition, there was no epidemic crisis plan. The Centre also did not have written procedures for specimen collection, transportation, labelling, rejection criteria, logging in, processing or storage. All specimens collected at the SARI/ILI 
sites receive a unique identification number and one data collection form is filled in. Virological data are analysed every 4 months, but only minimum epidemiological information is collected for each specimen. No epidemiological data are collected on SARI cases admitted to the designated hospitals. The specimen test results are shared every 4 months with the influenza surveillance unit at MOPH. When reagents and other supplies are available, all positive specimens and $10 \%$ of negative samples are sent to NAMRU-3 for quality control, but no results from the samples sent were available.

The assessment also revealed that there was no channel for shipment of virus isolates as per International Air Transport Association (IATA) regulations and also no trained or licensed shipper (or number) for international shipment of isolates/infectious substances. The isolates were usually hand-carried to Cairo (NAMRU-3) by visiting NAMRU-3 staff during 2007-2011.

\section{Discussion}

This study describes the capacity and efforts of the national influenza surveillance system in Afghanistan during 2007 to 2014.

Overall between 2007 and 2012, the percentage of samples tested that were positive for influenza virus was $3.6 \%$. This positivity rate is much lower than that reported from neighbouring and Asian countries like Pakistan (24\%),
China (30\%), Bangladesh (10\%), and Jordan (9\%) (14-17), which have similar sentinel surveillance systems, and may suggest some underestimation. Nonetheless, it should be noted that after more than 3 decades of war and conflict, the system was able to detect and respond successfully to the novel influenza virus circulating during the influenza A (H1N1) pandemic in 2009.

Our assessment of the current situation in the surveillance sites and the NIC provides a good indication of the existing challenges to and gaps in the system. Evidence suggests that poor compliance with the use of case definition of SARI and ILI by surveillance staff can affect estimation of the burden of influenza virus in the country (18). Our findings show that compliance at the surveillance sites was low and that standardized surveillance guidelines and operating procedures at the sites are not readily available. Furthermore there was poor cold chain management during sample transportation by local private transport, which affects the quality of samples received at the NIC. The NIC was able to perform the influenza PCR tests and virus isolation regularly up to 2011 , and played a major role in confirming the pandemic influenza A (H1N1) in 2009. At that time, the NIC was well supported by NAMRU-3 (19) until the level of funding by CDC declined. Thereafter, the capacity of the NIC decreased to a suboptimal level for virus isolation. Similarly, poor biosecurity measures, lack of a laboratory inventory system, standard test algorithms, contingency plans, and unavailability of and/or poor compliance with updated laboratory guidelines and standard operating procedures have also affected the quality of the performance of the NIC.

Despite these gaps and limitations, the national influenza surveillance system can and should be rejuvenated. This can be done by: introducing updated surveillance guidelines (adapted to the Afghan context), strengthening the capacity of surveillance staff, adopting an inventory system and contingency plan in the NIC. In addition, quality control of the system needs to be ensured through close monitoring of specimen collection, storage and transportation. Performing laboratory testing procedures on a regular basis and sharing results would also motivate the surveillance sites to regularly collect samples from SARI/ILI cases.

\section{Acknowledgements}

The authors express their sincere gratitude to the staff of the Ministry of Public Health, including provincial public health directorates and DEWS surveillance staff, and also to the WHO Country Office for their cooperation and technical support.

Funding: Technical and financial support for this assessment was received from the WHO PIP project in the WHO Eastern Mediterranean Region.

Competing interests: None declared.

\section{References}

1. The World Bank. Afghanistan: country overview [webpage] [http://www.worldbank.org/en/country/afghanistan/overview, accessed 30 August 2016].

2. Islamic Republic of Afghanistan, Permanent Mission of Afghanistan to the United Nations in New York. The situation in Afghanistan and its implications for international peace and security [website] [http://afghanistan-un.org/2009/06/ situation-in-afghanistan-and-its-implications-for-international-peace-and-security/, accessed 12 August 2016]

3. United Nations Assistance Mission in Afghanistan (UNAMA). Strategic Communications. Briefing to the United Nations Security Council by the Secretary-General's Special Representative for Afghanistan, Nicholas Haysom. New York,18 December 2014 [https://unama.unmissions.org/sites/default/ 
files/december_18_2014_srsg_briefing_security_council-eng. pdf, accessed 8 August 2016]

4. World Health Organization. Afghanistan WHO statistica profile. [http://www.who.int/gho/countries/afg.pdf?ua=1, accessed 22 August 2016].

5. Afghanistan multiple indicator cluster survey 2010-2011: Final report. Kabul: Central Statistics Organisation and United Nations Children's Fund; 2012 (http://reliefweb.int/sites/ reliefweb.int/files/resources/AMICS-Jun24-2012-FINAL..pdf, accessed 30 August 2016).

6. Gayer M, Legros D, Formenty P, Connolly MA. Conflict and emerging infectious diseases. Emerg Infect Dis. 2007 Nov;13(11):1625-31. PMID:18217543

7. Leslie T, Billaud J, Mofleh J, Mustafa L, Yingst S. Knowledge, attitudes, and practices regarding avian influenza (H5N1), Afghanistan. Emerg Infect Dis. 2008 Sep;14(9):1459-61. PMID:18760020

8. Communicable diseases in the Eastern Mediterranean Region: prevention and control 2005-2009. Cairo: WHO Regional Office for the Eastern Mediterranean; 2011.

9. Update on highly pathogenic avian influenza in animals: Afghanistan. Paris: World Organisation for Animal Health; 2009 (OIE Ref: 8130).( http://www.oie.int/animal-health-in-theworld/update-on-avian-influenza/2006/ accessed 30 August 2016)

10. Disease Early Warning System (DEWS) annual report 2009. Kabul, Afghanistan, Surveillance Directorate, Ministry of Public Health, 2009.

11. Ministry of Public Health Afghanistan, Surveillance Directorate. Disease Early Warning System(DEWS). Surveillance and Early Detection of Communicable Diseases. Annual report 2010 (http://moph.gov.af/Content/Media/Documents/DEWSAnnualReport2010Final206201293919404553325325.pdf, accessed 30 August 2016).

12. International Influenza Surveillance Assessment Tool. National Center for Immunization \& Respiratory Diseases, Influenza
Division, CDC (https://www.cdc.gov/flu/pdf/international/ cdc_flu_surveillance_tool_508.pdf, accessed 30 August 2016).

13. Global epidemiological surveillance standards for influenza. Geneva: World Health Organization; 2013 (http://www.who. int/influenza/resources/documents/WHO_Epidemiological_Influenza_Surveillance_Standards_2014.pdf, accessed 30 August 2016).

14. Badar N, Bashir Aamir U, Mehmood MR, Nisar N, Alam MM, Kazi BM, et al. Influenza virus surveillance in Pakistan during 2008-2011; PLoS One. 2013 Nov 8;8(11):e79959. PMID: 24260327

15. Yang P, Duan W, Lv M, Shi W, Peng X, Wang X, et al. Review of an influenza surveillance system, Beijing, People's Republic of China. Emerg Infect Dis. 2009 Oct;15(10):1603-8. 10.3201/ eid1510.081040 PMID:19861053

16. Zaman RU, Alamgir ASM, Rahman M, Azziz-Baumgartner E, Gurley ES, Sharker MAY, et al. Influenza in outpatient ILI casepatients in national hospital-based surveillance, Bangladesh, 2007-2008. PLoS One. 200912 29;4(12):e8452. 10.1371/journal.pone.0008452 PMID:20041114

17. Al-Abdallat M, Dawson P, Haddadin AJ, El-Shoubary W, Dueger E, Al-Sanouri T, et al. Influenza hospitalization epidemiology from a severe acute respiratory infection surveillance system in Jordan, January 2008-February 2014. Influenza Other Respir Viruses. 2016 Mar;10(2):91-7. 10.1111/irv.12354 PMID:26505620

18. Hirve S, Chadha M, Lele P, Lafond KE, Deoshatwar A, Sambhudas $\mathrm{S}$, et al. Performance of case definitions used for influenza surveillance among hospitalized patients in a rural area of India. Bull World Health Organ. 2012 Nov 1;90(11):804-12. 10.2471/BLT.12.108837. PMID:23226892

19. Elyan DS, Monestersky JH, Wasfy MO, Noormal B, Oyofo BA. Capacity building of public health laboratories in Afghanistan: challenges and successes (2007-2011). East Mediterr Health J. 2014 Mar 13;20(2):112-9. PMID:24945560 